\title{
Posing the Hair against the Head: Global Experiences and Gu Wenda's Installations of a Utopia
}

\author{
Hongbing Zhang \\ Fayetteville State University, Fayetteville, NC, USA \\ Email: hzhang1@uncfsu.edu
}

Received 23 July 2015; accepted 5 October 2015; published 8 October 2015

Copyright (C) 2015 by author and Scientific Research Publishing Inc.

This work is licensed under the Creative Commons Attribution International License (CC BY). http://creativecommons.org/licenses/by/4.0/

\section{c) (i) Open Access}

\begin{abstract}
The Chinese artist Gu Wenda's installation art series United Nations and Odepus Refound were created after the artist moved to the USA in 1987. In these two art projects, Gu used the human hair and other bodily materials, which marked a big difference and departure from some of his most famous art works using (faked) traditional Chinese writings. This turn to the human body had a lot to do with the artist's global experiences and his newly gained sense of identity. This paper examined some of the art projects in the two installation series and analyzed how the artist used the human bodily materials-especially the human hair-to challenge the established identities of nation and culture formed in the modern world. In the process, it also endeavored to stake out ideologically what kind of utopia behind the artist's heroic challenges.
\end{abstract}

Keywords

Contemporary Chinese Art, Utopia, Human Materials, Installation Art, Global Experiences, Gu Wenda

\section{Introduction}

The shift of interest in the artwork of contemporary Chinese artist Gu Wenda (1955-) paralleled his departure from China and arrival in the United States in 1987. While he was in China, he created many paintings and installations on meaningless and fake Chinese ideograms to challenge the Chinese perceptions of cultural tradition and meaning-productions, after arriving in the US, he started to focus on the human bodily materials in his artwork. Such a change maight have a lot to do with his global experiences around the world and his newly experienced sense of racial, cultural and national identity that prompted him to think about what constituted the basic common ground and difference between peoples, cultures and nations on a global scale. 
Starting in 1989, Gu created two major series of installation artwork titled United Nations and Odepus Refound. In this paper, I am going to discuss how Gu uses in some of the two installation series the human bodily materials - specially the human hair-to stake out his ideological positions and dispositions and to articulate his utopian desire in his heroic challenges to the well established identities of culture and nation in world today.

\section{The Political Economy of the Hair and the Head}

The challenge Gu Wenda's artwork posed after he moved to the US can be seen in the first division of the project United Nations-Poland Monument: Hospitalized History Museum in 1993. In this installation, he draped the interiors - the hall, the grand staircase and the foyer — of the History Museum in Lodz, Poland, with white sheets borrowed from a local mental hospital and scattered it with hair collected from local barbershops. He also put in the exhibition hall sheet-covered empty chairs, metal beds borrowed from the hospital, a large table and some books, all of which were mingled with snippets of hair. The scattered hair, and the macabre atmosphere created therein, evoked in viewers memories of the Nazi Holocaust. This installation, supposedly "not making a point about Poland in particular but how history is created by mentally ill people” (Mehugh, 1997), lasted only one day: it was closed down the next day because it was said to be too much for the Jewish community in Lodz (see Figure 1). The harrowing memories point to a tragic historical fact that the otherwise organic relationship between the hair, the head and the body was turned by Nazi atrocities into a mere metonymy in both the rhetorical and physical sense-now the hair was cut off physically from the head, and it was this physical separation of the hair from the head that made its relation to the head irreversibly rhetorical. The hair at the installation reminded viewers that the head and the body lost their physical presence in the sight and even in people's life during the Nazi period. The hair scattered in the symbolic space of the hospitalized museum challenged the head and mind of the viewers with memories of lives lost in the Holocaust. In this light, Gu's installation was to test whether post-Nazi people would have the courage to turn their heads back to history and face the memories of historical atrocities. In particular, it was also a challenge posed to the head of the museum-the curator - to see to what extent the irruption of repressed emotions and memories aroused by the hair could be allowed into the order of an art and historical institution and into the social, political and symbolic fields of current human life at large.

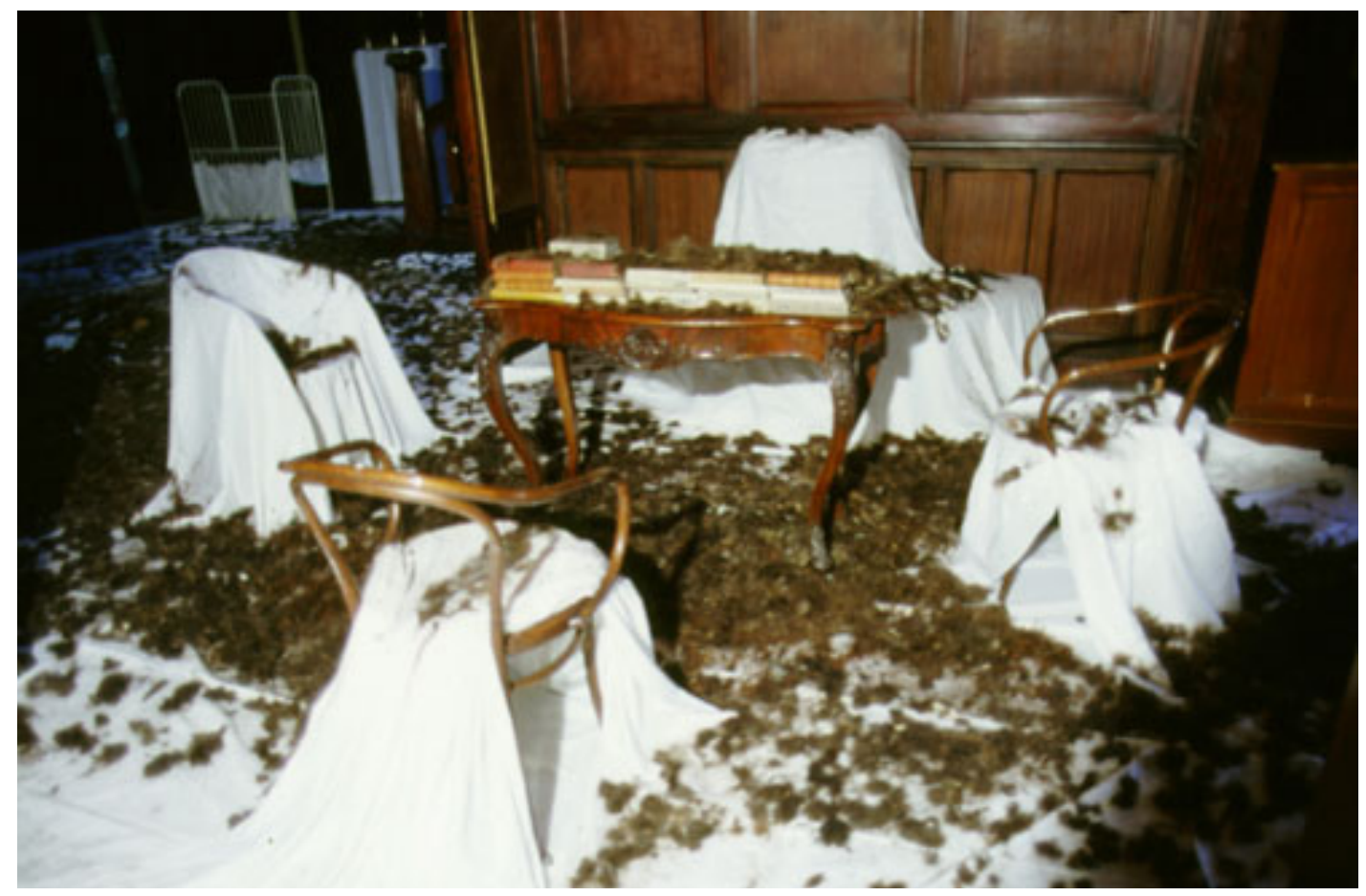

Figure 1. United nations_-Poland monument: Hospitalized History Museum, Lodz, Poland, 1993. 
The shorn hair that Gu Wenda put in the Polish museum as an art exhibit also forces us to reconsider such fundamental issues as the body economy and politics, and by extension, civilization and its discontents. Although the hair grows out of the head, it has not obtained the same status and power as the head has within the economy of our body; it has often been fixed in a subordinate, even antagonistically repressed relationship to the head. The Chinese saying “toufa chang, jianshi duan (头发长见识短)", which literally means “those who have long hair are those who have short vision”, captures the very uneven and unequal significance between the head and the hair in our body economy: the eye has been given a significant position because it can increase the income of knowledge and wisdom in our head whereas the hair not only can add nothing to our head but, on the contrary, it consumes our energy like a parasite on the head. The fact that this saying in the Chinese society is traditionally taken to be an image of women leads us to see how the bodily hierarchical order is constructed and appropriated almost inadvertently by the patriarchal order in the practice of our everyday life. In the Chinese Qing dynasty and the early Republic, the tensions between the hair and the head were closely related to the racial consciousness of the Han Chinese: the Manchu rule of China is metonymically taken by the Han Chinese as an unnatural rule of the Manchu hair-style over the Chinese head.

Discussing hair's "peculiar nature of representative of the individual vital force and spirituality" in the Western tradition (Sartor, 1994: p. 92), Monique Sartor, in her analysis of Gu Wenda's United Nations-Italy Monument: God \& Children, asserts that "the hair has a wealth of psychological and political connotations too, as everyone from Samson to Freud has known”. Kim Levin, in his review of Gu's hair-work, points out, "power is inherent in those slender outgrowths of the epidermis, those pigmented filaments that are among the most animalistic and intimate elements of the human body" (Levin, 1994: p. 69). The words "the most animalistic and intimate" used here register a paradoxical status of the hair within the economy of the human body. It is obvious that, while stressing the power and vitality of the hair, both Sartor and Levin imply in their articles a psychological, social and even political distance and discordance between the hair and the head: here the power and vitality of the hair are constructed deliberately as something different from-and in sharp contrast to- those of the head. In the secular traditions in both China and the West, the hair, though growing on the top of the human body, has always been symbolically assigned to what the Russian theorist Mikhail Bakhtin calls "the lower bodily stratum", which includes foot, belly, genitalia, menstrual blood, sweat, sputum, urine and shit, and which has always been looked down upon by the "higher bodily stratum" such as the head and the eye (Bakhtin, 1984). Viewed in this light, the thrust of Gu Wenda's hair-work installations in public has gained an appropriate focus: it forces us to re-examine the relationship between the head and the hair, civilization and its discontents. The close-down of the hair installation in Poland has indexed, in a performative and forceful way, the expected results that Gu's installation was supposed to obtain, but it has also registered in the meantime the persistence of such a hierarchical order within the economy of our body and civilization.

Coming from the "lower bodily stratum" like menstrual blood, the hair as an art material connotes a special meaning for Gu Wenda. In an interview held in 1996, he says, "shortly after my arrival [in USA], I began to work on my Oedipus Refound series which uses body-related materials, like menstrual blood and hair, to explore what I see as fundamental realities for all cultures. I call these my 'found subjects' as opposed to the Duchampian 'found objects'. That's not to say that I was necessarily influenced by Duchamp. His ideas are cool and detached while my themes are emotional and heated" (Lutfy, 1996: p. 51). Gu's distinction between the "found subjects" and the "found objects" as a way to differentiate and distance himself from Duchamp points to the unique status of the menstrual blood and the hair in the dichotomy between the subject and the object, the self and the other. The menstrual blood and the hair are part of the subject and the self but have always been repressed, displaced or simply rejected as if they were something alien from outside, or simply as objects. However, these liminal bodily materials, which are "monsters" of the hyphenated and hybrid subject-object and selfother and which challenge the well-protected boundaries of our disciplining and disciplined civilization, are taken by Gu as "universal materials" in the sense that "they are basic to human life" and in this very sense basic to art as well (Lutfy, 1996: p. 56). To him, it is these basic bodily materials which always come out of our body and escape the boundaries between the self and the other, as demarcated, controlled and authorized by the head that form the basis of human life and communication. And it is in this sense that we can understand that Gu's installations with the body-related materials are at once, to use his own words, "a kind of deconstruction of human body" (Lutfy, 1996: p. 56) and a construction of a utopia-a utopia free of all those forced boundaries and demarcations. The de-constructive gesture is aimed, on the one hand, at the head-oriented and head-centered body economy and politics and, on the other, at the self-centered and interior-exterior dichotomized perception of 
human existence. This subversive spirit, as exhibited in the selection of both the material and theme for Gu's artwork, has run all through his Oedipus Refound series and the United Nations project.

\section{The Menstrual Blood as a Tamed Challenge}

Gu Wenda's Oedipus Refound series mark the beginning of a transition to the Western cultural environment and the use of what he calls "the found subjects" from the lower bodily stratum-the menstrual blood, the placenta and the human hair - as materials for his installation art since he came to the US in 1987. This series dates back to 1989 and deals with what he calls "the physical cycles of conception, birth and death" (Lutfy, 1996: p. 56). In the first piece, Oedipus Refound: Two Thousand Natural Deaths (1989-1992, New York), Gu used 500 used menstrual tampons, napkins with personal statements from women donators and put them in glass coffins. In one of the glass coffins, the menstrual tampons and napkins were placed right on the words "Holy Bible". This gesture was made, I would argue, less as a sacrilege of Christianity than as a "bloody" rem(a)inder of the holy spirit. What it really challenges, more than merely as a feminist statement of the unique role of women in the cycle of life and death, is whether we have the courage to see in public, with our own eyes, what we have endeavored to repress, hide or simply deny as part of our life and death. Together with the personal statements made by the women donators of these tampons and napkins, the menstrual blood, as a forever witness to the failure of human efforts to sublimating at the dictates of the head, speaks the loudest - and in its immediate visibility — not only for women but also for the lower bodily stratum that has been denigrated in the political economy of body.

However, the seeming immediacy of the menstrual blood in the eyes of the viewers was only an optical illusion in all its senses: between the viewers' eyes and the exhibited menstrual blood, there was the glass of the coffin boxes. The glass allowed the viewers to see the so-called "natural deaths" of some would-have-been lives displayed there, giving a visibility and a sense of unobstructed immediacy to the otherwise kept-private and thus repressed menstrual blood. But with its transparency, the glass also tended to hide its function of insulation and separation. It separated the viewers from the menstrual blood, and prevented the possible "disgusting smell" from coming out of the boxes to disturb their mood while appreciating the art that was placed in front of their eyes.

Here the installation art offered just a one-way traffic of communication, regulated and controlled by the glass, between the exhibited menstrual blood and the viewers: the eyes could see through the glass to the menstrual blood but the blood was not allowed to come out of the glass and disgust the viewers with its smell. The ambivalent position of $\mathrm{Gu}$ is also obvious here: by using glass as an intervention, he managed to bring the challenge and protest of menstrual blood immediately to the eye but he also disciplined and distanced the blood for the eye with the glass installed there as an invisible protective wall. Encasing the menstrual blood in the glass coffins as exhibits on display, he thus greatly undermined the challenge and protest of the menstrual blood, though he succeeded in displaying in a visual form the fetishism and nostalgia for the origins of life (and death) that comes from women and the lower stratum of their bodies.

\section{The Hair as an Ideologeme: The China Factor in the British Colonialist Story}

Gu Wenda's United Nations project grew out of his Oedipus Refound series: the Polish division, which marks the beginning of the United Nations project, originated as part four of Oedipus Refound. So it is no surprise to find that there was an explicit continuity between these two projects, which embody a new direction in Gu's artistic activities after he moved to the US. According to Gu himself, this new direction was "to push both conceptual and formal to extremes [sic], parallel and separate, two parts within one individual work, and the oppositions have the same structures" (Levin, 1994: p. 68).

Such a parallel and separate structure is indeed visible throughout the United Nations project. In United Nations-Britain Monument: The Maze (Nottingham, 1996), Gu Wenda used nine hundred poppy flowers from Asia to decorate a big lampshade on the floor and it was surrounded by the shorn hair of the British people. With the hair, he also wove a huge British flag and fifty-three flags of the Commonwealth nations; the flags were hung from the wall. Up on one wall, he wrote one English sentence with the hair, which went like this: "ONCE UPON A TIME THERE WAS A BRITISH MERCHANT WHO SAID IMAGINE IF EVERY CHINESE WEARS ONE MORE INCH OF CLOTHING”. Interestingly enough, this sentence was written in an order that is primarily found in the classical Chinese text—from top to bottom and from right to left—and which registers 
a Chinese perspective on the British history and a China factor behind the British success.

Putting light on the inside, Gu turned the lampshade of poppy flowers into a magnificent crown, attractive and mysterious. The poppy flowers were the same kind of poppy flowers from which the British extracted opium and exported it into China about one and a half century ago. This poppy encounter between the British and the Chinese was recorded in the Chinese history book and in the memory of the Chinese people as the Opium War; and, as a result of the war, the British cloth was able to enter China and make tremendous profit. The poppy flowers on the lampshade-turned-crown were meant to tell the viewers an untold and un-tell-able story in Britain: in its history from the industrial revolution (as symbolized by the electrical lampshade) to an imperial empire (as symbolized by the magnificent crown), it was the colonial profit that made such a historical change possible and thus created the success for Britain that we have seen today. By surrounding the lampshade-turned-crown with the hair shorn from the heads of British people and by lowering it to the same level of the floor on which the feet of viewers treaded, Gu tried, on the one hand, to point out that such a colonialist story was repressed and denigrated in the maze of a successful Britain. The spatial relationship between the huge British flag and the fiftythree small flags of its Commonwealth nations, which were hung high up on the wall as a symbol of the British success, and the low place of the lamp-turned-crown on the floor was purported by the artist to further illuminate the fact that the colonialist story tends to be separated from the story of British success: the viewers tended to see with their eyes the flags of success on the wall and to tread with their feet the colonialist fact on the floor (see Figure 2).

On the other hand, by the same act of using the poppy flowers to transform the lampshade into a crown and lowering the lampshade-turned-crown to the same level of the downtrodden on the floor, the move to surround the crown and weave the flags with the denigrated hair-in other words, by engaging all these in the act of the hair-work as art, Gu Wenda also endeavored to de-mythologize the myth of British success and achieve a disenchantment with the "Maze" of Great Britain. It is in this sense that such artistic materials as the poppy flowers and the human hair become what Fredric Jameson would call artistic "ideologemes" which serve as "both a conceptual description and a narrative manifestation all at once" (Jameson, 1981: p. 87). By organizing the poppy flowers and the hair as ideologemes into his installation, Gu was able to offer a symbolic description of

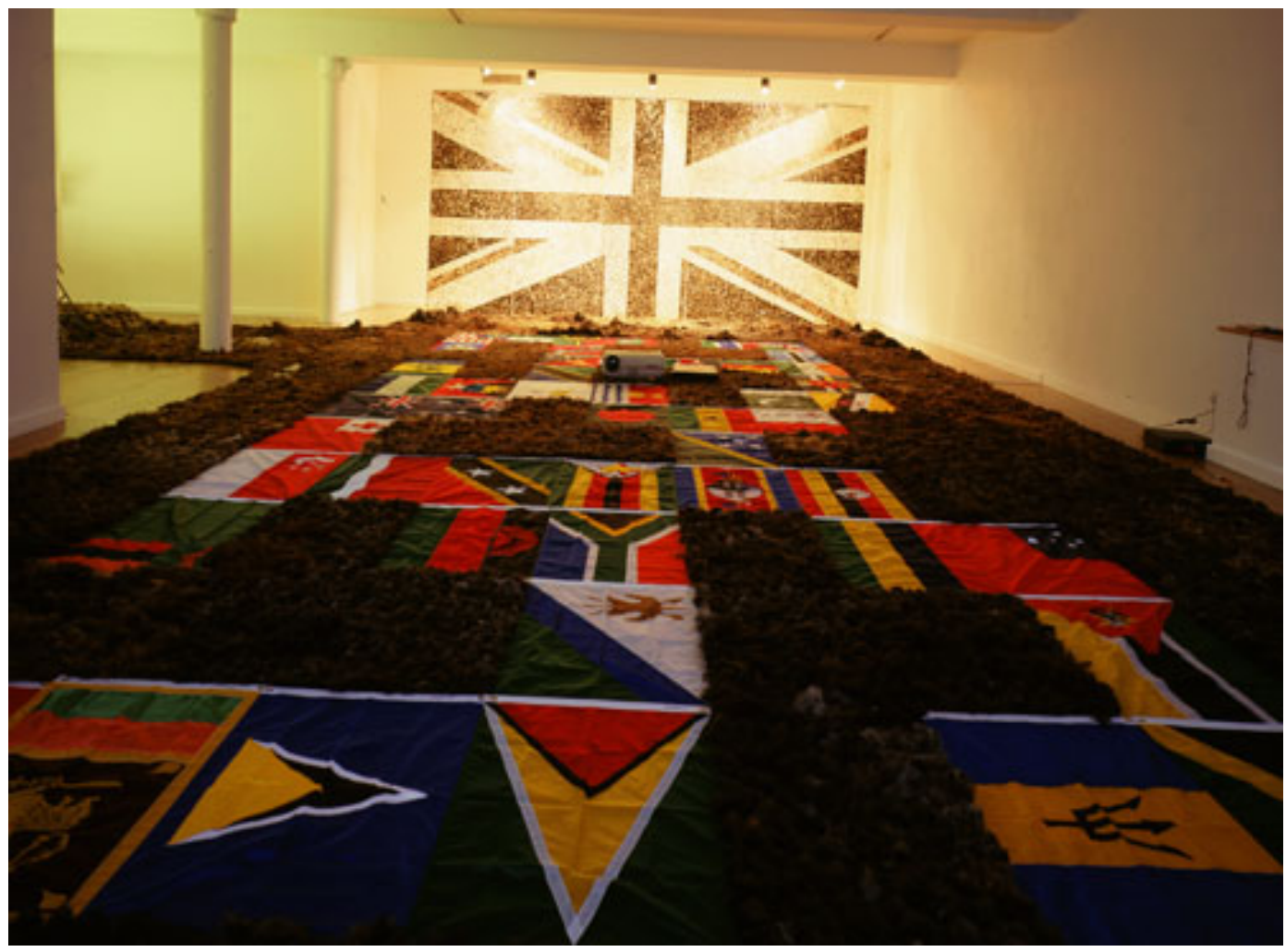

Figure 2. United Nations_-Britain monument: The Maze, Nottingham, UK, 1996. 
the history of Great Britain from its industrial revolution to colonialism and imperialism, and to make his comment on such a history from a Chinese perspective-from that of a people who were the victims of such colonialist and imperialist act.

The sentence that "ONCE UPON A TIME THERE WAS A BRITISH MERCHANT WHO SAID IMAGINE IF EVERY CHINESE WEARS ONE MORE INCH OF CLOTHING” is an incomplete sentence: it ends with the "if" clause but without providing the main sentence with the possible result. By putting such an incomplete sentence upon the wall as high as the flags and using the same material—human hair-to make the sentence and weave the flags, Gu managed to restage the colonial desire that is often hidden in the dustbin of history. Juxtaposing the flags and the incomplete sentence high on the wall, Gu was able to disclose how the myth that the British success was achieved by selling to the rest of the world the high-quality products (as a result of the industrial revolution only) has been created. However, the hair that associated the incomplete sentence on the wall with the flags also functions to connect them with those on the floor: the poppy flowers on the lampshadeturned-crown on the floor were always telling the viewers the other half of the story that the myth on the wall was created to hide and cover up.

The classical Chinese way of writing an English sentence has a lot of implications here. On the one hand, it forces the viewers to see the British history and culture from the perspective of the victims of British colonist and imperialist act, and thus threw some light on the blind-spot of the "British Maze" in the eyes of the viewers. On the other hand, it also registers a specific historical presence and involvement of the Chinese in the maze of Britain: as the Chinese way of writing cannot be directly seen at first sight, its "absent presence" in the English sentence, just like the glamorous poppy flowers, could be the haunting "ghosts" of the victims of the opium and the Opium War. Yet, given the fact that the Chinese way of writing is not even practiced in most part of China today, its "absent presence" in the English sentence here is destined to be turned into a "present absence" and in turn it is bound to be marginalized, ghostlike and "classical". The myth on the wall and the de-mythologizing evidence on the floor were nevertheless connected and combined in the installation artwork into a harmony by the same material - the shorn hair. Gu's balanced aesthetic of "parallel and separate" only serves here to remind us what the "materialization of ideology in external materiality" (Zizek, 1997: p. 4) hid and revealed: the imbalance in the power relationship between the colonizer and the colonized. In a world of such imbalanced power, harmony, even in the sphere of art, is bound to be only a utopia.

\section{Conclusion: The Hair and the Installations of a Utopia}

In the project United Nations-Britain: The Maze, the pursuit of harmony in form and the use of the human hair as its material are no doubt the most important elements incorporated into the content—subject matters—of Gu Wenda's efforts to unpack the truth behind the modern myth of Great Britain. In the project Holland Monument: V.O.C.-W.I.C. (Netherlands, 1994) and Hong Kong Monument: The Historical Clash (Hong Kong, 1997), he explored the same relationship between colonial history and present-day reality. In Italy Monument: God \& Children (Milan, 1994), Israel Monument: The Holy Land (Israel, 1995) and Africa Monument: The Praying Wall (South Africa, 1997), he examined the relationship between the religiosity of life and history. In all these works, Gu tried to use the hair as the most significant material to install a utopia of harmony in form.

It could be argued that the utopia of harmony Gu Wenda tried to construct was one of a new communication and connection between the hair and the head, between life, body and knowledge, between the self and the other, and between civilization and its discontents. Gu was acutely aware that his installations of a utopia were themselves utopian in nature: "The main goal of the United Nations project is to achieve the impossibilities of civilization, history, politics and ethnicity. This is a wonderful utopian [sic] can be fully realized in my art through extreme efforts only" (Sartor, 1994: p. 94). It was a heroic act to construct such a utopia against today's globalized world - an act also endowed with what Kim Levin calls "more than a modicum of the old avant-garde shock value” (Levin, 1994: p. 72). But, such a heroic and utopian act contained an undeniable danger: by using hair in its deconstruction and subversion of the head-figure of colonial, imperial, epistemological and cultural hegemony in the world, it tended to deny the present identity and reality of women and the colonized people. In this sense, the utopian and heroic behavior of the artist was on the verge of becoming an escapist move.

\section{References}

Bakhtin, M. (1984). Rabelai and His World (H. Iswolskytrans.). Indiana: Indiana University Press. 
Jameson, F. (1981). The Political Unconscious: Narrative as a Socially Symbolic Act. Ithaca, New York: Cornell University Press.

Mehugh, F. (1997). Art Unites Nations with a Hair-Raising Power. South China Morning Post, 23, .Hong Kong: South China Morning Post.

Lutfy, G. (1996). Asian Artists in America: Wenda Gu. Atelier-International Art Magazine, 11, 49-58.

Levin, K. (1994). Splitting Hairs: Wenda Gu’s Primal Projects and Material Misunderstandings. United Nations—Italian Division Catalogue (pp. 67-78). Milan, Italy: Enrico Gariboldi Arte Contemporanea.

Sartor, M. (1994). United Nations. United Nations_Italian Division Catalogue (pp. 91-94). Milan, Italy: Enrico Gariboldi Arte Contemporanea.

Zizek, S. (1997). The Plague of Fantasy. London and New York: Verso. 